\title{
Parasitism, seasonality, and diversity of trombiculid mites (Trombidiformes: Parasitengona, Trombiculidae) infesting bats (Chiroptera) in Poland
}

\author{
Paula Zajkowska $^{1}$ (D) Joanna Mąkol ${ }^{1}$ (D)
}

Received: 21 August 2021 / Accepted: 27 November 2021 / Published online: 7 December 2021

(c) The Author(s) 2021

\begin{abstract}
The study aims to ascertain the diversity of trombiculid species associated with Chiroptera in Poland, and for the first time in the case of research on Central European Trombiculidae, we use both DNA and morphology in an integrative taxonomic approach to determine species identities of trombiculids. The research was carried out from 2015 to 2019. In total, 2725 larvae were collected from 300 specimens of bats belonging to 11 species. Deutonymphs were obtained through laboratory rearing of larvae; few larvae and deutonymphs were collected also from bats' daily roosts. The presence of trombiculid larvae on hosts was observed between July and April of the following year, with the highest numbers recorded in autumn, during bat swarming. Male bats were infested more often than females (16.4 vs. 6.6\%). The highest infestation rate was recorded for Barbastella barbastellus, Myotis nattereri and Plecotus auritus, and the highest prevalence of chiggers (>30\%) for Myotis bechsteinii and $P$. auritus. The larvae found on bats occupied the areas with free access to the host's skin: auricles, tragus, and snout. Morphological identification of specimens to the species level was hindered by the mosaic distribution of diagnostic traits. Morphological analyses indicated the presence of Leptotrombidium russicum and Leptotrombidium spp. in the examined material, whereas molecular analyses additionally suggested three other potential species assigned to the same genus based on the assessed scope of intrageneric variation (ASAP method). We argue that the identification of the parasitic larvae (chiggers) using morphological characters does not address the question of actual species boundaries, which, in turn, affects the inferences about host specificity and host range.
\end{abstract}

Keywords Leptotrombidium spp. · Morphology · COI · Phenology $\cdot$ Host range · Attachment sites, Chiggers

Paula Zajkowska

paula.zajkowska@upwr.edu.pl

1 Department of Invertebrate Systematics and Ecology, Wrocław University of Environmental and Life Sciences, Kożuchowska 5b, 51-631 Wrocław, Poland 


\section{Introduction}

Trombiculidae sensu Kudryashova (1998), with more than 3000 nominal species worldwide (Liu et al. 2013; Nielsen et al. 2021), is the most species-rich family within terrestrial Parasitengona mites. Most species, recognized based solely on morphological criteria, are known exclusively from larvae, which parasitize various vertebrate and a few invertebrate hosts (Nadchatram 2006; Wohltmann et al. 2006; Shatrov and Kudryashova 2008; Stekolnikov and Kar 2015; Stekolnikov et al. 2016; Caputo et al. 2018; Felska et al. 2018; Kaya and Yilmaz 2019). Despite the large number of papers related to Trombiculidae (Actinotrichida: Parasitengona) published during the last 80 years, knowledge about ecological demands and biology of species remained scarce. This is in particular true in case of chiggers associated with bats (Chiroptera).

More than 400 nominal species of chiggers have been reported as parasites of Chiroptera worldwide (Zajkowska et al. 2018; Bassini-Silva et al. 2021; Kalúz et al. 2021; Ševčík et al. 2021), but only two of them-Leptotrombidium russicum (Oudemans) and Oudemansidium musca (Oudemans) - have been recorded from bats in Poland (Moniuszko and Mąkol 2014). A roughly similar representation of bat-associated chiggers has been noted in other Central European countries, e.g., the Czech Republic [L. russicum and $O$. musca but also Oudemansidium komareki (Daniel \& Dusbábek), Neotrombicula autumnalis (Shaw) and Neotrombicula japonica (Tanaka et al.)], Slovakia (L. russicum, O. musca, O. komareki), and Hungary (L. russicum) (Zajkowska et al. 2018). Both $N$. autumnalis and $N$. japonica have also been recorded from Poland, but the findings referred to associations of these species with rodents, soricomorphs, and in the case of N. japonica, also carnivores (Moniuszko and Mąkol 2014).

So far, 1402 bat species belonging to 21 families have been described in the world (Wilson and Mittermeier 2019). In Poland, the presence of 27 species (1.9\% of the world's fauna of bats), aggregated in the families Vespertilionidae (24 species), Rhinolophidae (two species) and Miniopteridae (one species), has been confirmed (Okarma et al., https://www.iop.krakow.pl/Ssaki/gatunki; Piksa and Gubała 2020). Of those, as many as 14 species have been hitherto recorded in Poland as hosts of trombiculid larvae of the genera Leptotrombidium (L. russicum) (12 bat species) and Oudemansidium (O. musca) (four bat species) (Willmann 1952; Harmata 1967; Haitlinger and Ruprecht 1977, 1985, 1992; Haitlinger 1979; Haitlinger and Łupicki 2008; Moniuszko and Mąkol 2014).

According to some authors (e.g., Shatrov and Kudryashova 2006), the host specificity of trombiculid mites is extremely low, and habitat preferences rather than phylogenetic affiliation of the host plays a crucial role in host selection. The number of host species (host range) exploited by these parasites is deemed to become defined at higher taxonomic levels; however, the frequency of infestation (prevalence) of a given host species remains unknown. The actual host specificity may be negatively influenced by incorrect identification of the trombiculid larvae, especially when based exclusively on morphological evidence. Nevertheless, of all hitherto recognized associations between chiggers and their hosts, the genera and species which exploit bats are considered the most hostspecific (Shatrov and Kudryashova 2006; Stekolnikov and Quetglas 2019).

The present study aims to ascertain the diversity of trombiculid species associated with Chiroptera in Poland, using both morphological and molecular criteria, which should translate to improved understanding of host range and host specificity of batassociated chiggers. 


\section{Materials and methods}

\section{Sampling}

The field work was carried out from 2015 to 2019. All bats were caught under permits (DZP-WG.6401.09.05.2015.km.7, DZP-WG.6401.09.12.2016/2017.dł.2) issued by the General Directorate for Environmental Protection and within the frame of cooperation with Polish chiropterologists. Trapping of bats was conducted using mist nets and/or a harp trap $(1.5 \times 2 \mathrm{~m})$. Each bat was temporarily transferred to a cotton bag, to avoid cross-contamination with trombiculid larvae. In ascertaining the taxonomic affiliation and sex of bats the identification key to the bats of Europe was used (Dietz and von Helversen 2004). In winter, due to the limited access to hibernacula and the restrictions in capture of bats, the larvae were obtained only from available hosts, in compliance with bat protection rules.

Most trombiculid larvae removed from the hosts using smooth forceps, bent at $45^{\circ}$, were transferred directly to EtOH. The larvae at the highest level of engorgement were placed in rearing vials $(25 \times 35 \mathrm{~mm}$ glass containers, with semi-transparent lid). To obtain active postlarval forms for morphological analyses, laboratory rearing was carried out, within the parallel and independent experiment testing the development success to subsequent instars at laboratory conditions. Additionally, we searched the daily roosts of bats for engorged larvae that had dropped off their hosts as well as for representatives of active postlarval stages. For that purpose, $100-\mathrm{mL}$ containers filled with glycerol or EtOH were placed under/between loose chunks of bark and in frost cracks.

\section{Parasitological indices and attachment sites}

To determine the general parameters related to the level of infestation with trombiculid larvae, the prevalence, mean intensity and mean abundance (Bush et al. 1997; Whitaker et al. 2009) were estimated. Descriptive statistics, calculated collectively for ectoparasitic chiggers collected during the survey, were computed in R software (R Core Team), with application of R Studio (v.1.2.5033). In ascertaining the statistical significance of differences in infestation of bats' females and males the Mann-Whitney U test was applied. Differential use of attachment sites on the of host's body was analyzed in a descriptive manner.

\section{Morphological and molecular identification of Trombiculidae}

One hundred mites randomly selected from all samples (larvae collected from different host species, deutonymphs obtained by experimental rearing from larvae taken from hosts, deutonymphs and larvae collected from the daily roosts of bats) were subject to detailed morphological analyses. The material was mounted on microscopic slides in Faure's fluid (Walter and Krantz 2009). Measurements were taken using a Nikon Eclipse E600 compound microscope, equipped with differential interference contrast (DIC) and DS-Fi1 camera system, using the NIS-Elements BR software (https://www.microscope.healthcare. nikon.com/en_EU/products/software/nis-elements/nis-elements-basic-research). To identify larvae to genus and species we used various identification keys (Kudryashova 1998; Fernandes and Kulkarni 2003; Stekolnikov 2013), and in the case of deutonymphs, the 
original descriptions as well as redescriptions of species (Kepka 1959; Crossley 1960; Mąkol et al. 2010) served as a source.

For molecular analysis we used a non-destructive method of DNA extraction (Cruickshank 2002; Dabert et al. 2008; Porco et al. 2010) aimed at retaining the exoskeletons for morphological examination. The DNA extraction and polymerase chain reaction protocols (Bernard et al. 2019) were applied with the following modifications: only the bcdF01 primer and $12.5 \mu \mathrm{l}$ of KAPA2G Robust HotStart ReadyMix were used; the annealing temperature for PCR was $49{ }^{\circ} \mathrm{C}$. PCR assay was applied to amplify the fragment of the mitochondrial cytochrome $\mathrm{c}$ oxidase subunit I gene (COI). The amplification product was sequenced in both directions (Genomed, Poland). The obtained nucleotide sequences were analysed using the MEGA X program (Stecher et al. 2020) and Geneious v.9 (Kearse et al. 2012). The sequences are deposited in the GenBank (for accession numbers see Table 1, rows 5-8). The sequences for additional trombiculid species and outgroup taxa (Table 1 , rows 1-4, 9-20) were retrieved from GenBank.

The mites used for morphological analyses, including exoskeletons retained after DNA extraction, are deposited in the acarological collection of the Department of Invertebrate Systematics and Ecology, Wrocław University of Environmental and Life Sciences.

\section{Species delimitation and phylogenetic analyses}

For species delimitation of our specimens and those represented by sequence data in GenBank, we applied the default options of Assemble Species by Automatic Partitioning (ASAP) method (Puillandre et al. 2021), available at https://bioinfo.mnhn.fr/abi/public/asap. Genetic distances among sequences were estimated with Kimura-2 parameter (K2P) substitution model (Kimura 1980). The ASAP inference was used for trombiculid sequences derived from specimens collected from bats, bat roosts and from Leptotrombidium spp. sequences filed in the GenBank database (Table 1, rows 5-18). The partitions with the best asap-score (lowest value) were selected.

The Bayesian phylogenetic inference (BI) was performed with MrBayes (Ronquist and Huelsenbeck 2003; Ronquist et al. 2012) using Markov chain Monte Carlo (MCMC) algorithm and with the application of the following commands: ngen $=1000000$, samplefreq $=1000$, sump/sumt burnin $=250$. The phylogenetic tree visualization was made in FigTree v.1.4.4 (Rambaut 2018).

\section{Results}

The localities in which the ectoparasitic larvae were found on hosts covered the area spreading out between $49^{\circ} 12^{\prime} 0.194^{\prime \prime} \mathrm{N}-54^{\circ} 23^{\prime} 43.685^{\prime \prime} \mathrm{N}$ latitude and $14^{\circ} 36^{\prime} 53.64^{\prime \prime} \mathrm{E}-22^{\circ} 53^{\prime} 20.399^{\prime \prime} \mathrm{E}$ longitude, within the administrative borders of Poland (Fig. 1).

\section{Prevalence, intensity, and abundance}

Out of 2813 bats from 19 species, chiggers were observed on 300 individuals (10.7\%) from 11 species (Table 2). Larvae were not recorded on Eptesicus nilssonii, Myotis dasycneme, Myotis emarginatus, Myotis mystacinus, Nyctalus noctula, Pipistrellus nathusii, Pipistrellus pipistrellus, and Vespertilio murinus, for which a total of 474 specimens were caught. 


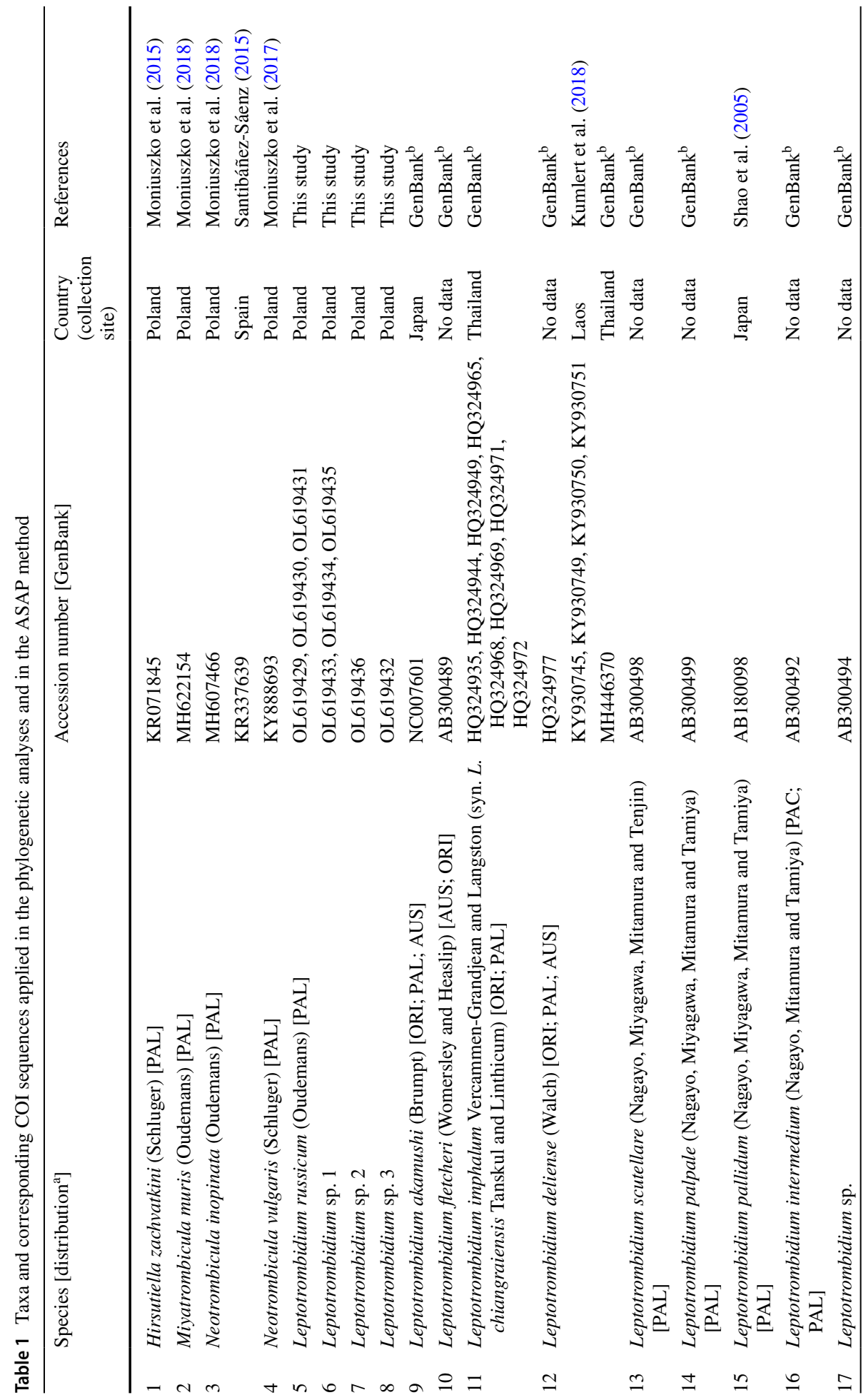




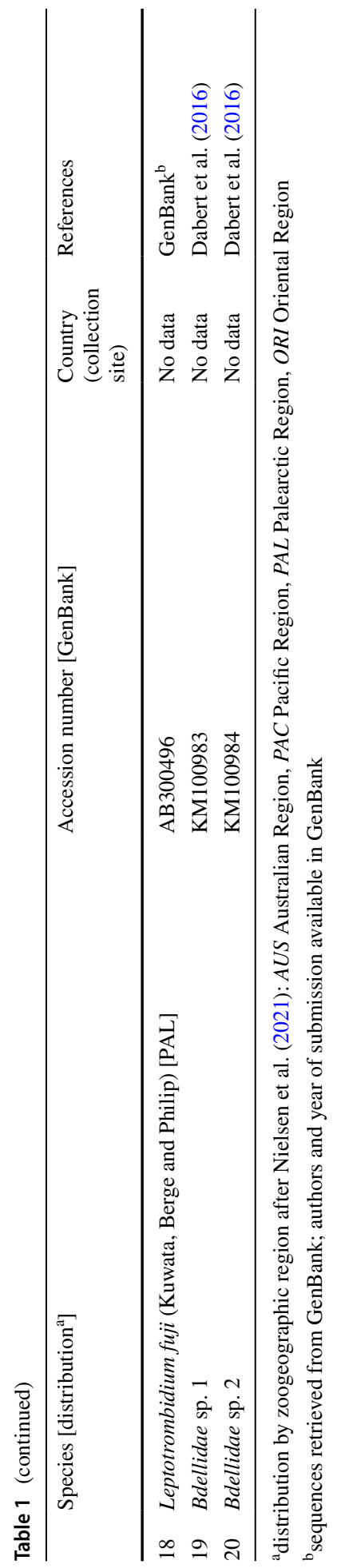




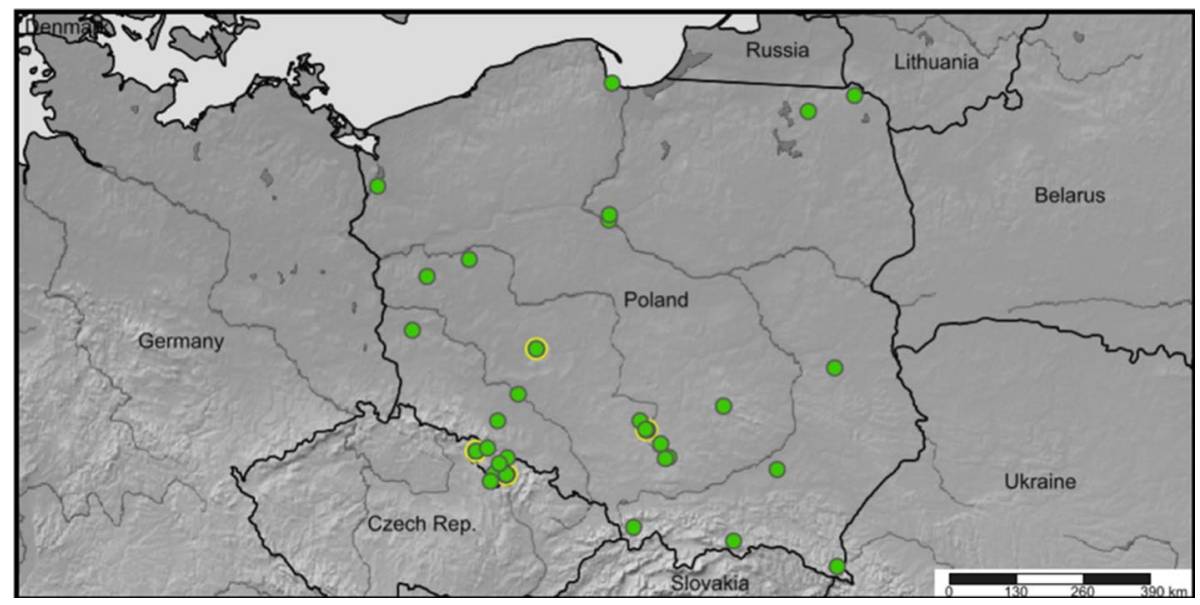

Fig. 1 Collecting sites of bat-infesting chiggers in Poland (36 localities recorded during present survey, in 2015-2019). Green dots: Trombiculidae; green dots with a yellow margin: L. russicum. (Color figure online)

Male bats constituted $81.3 \%$ of all infested host individuals and $16.4 \%$ of males representing species confirmed as hosts were parasitized by chiggers; the respective values for females were lower (18.7 and 6.6\%). Differences in infestation of females and males were significant (Mann-Whitney $\mathrm{U}$ test: $\mathrm{W}=4887.5, \mathrm{P}=0.008$ ). The only exception to a male bias in infestation was Rhinolophus hipposideros, in which, contrary to other species, the males were not infested; note, however, that the overall number of examined males was (much) lower than that of females for this species (Table 2). Altogether, 2725 trombiculid larvae were collected from these hosts. The highest infestation rate (prevalence) was recorded for Barbastella barbastellus, Myotis nattereri and Plecotus auritus, whereas the highest prevalence of chiggers (>30\%) was recorded for Myotis bechsteinii, P. auritus and $P$. austriacus (Table 2); however, in the case of $P$. austriacus the very high prevalence was due to a single individual of this species being infested.

\section{Seasonality in parasitism}

The only month in which no infested bats were observed was June (Fig. 2). The earliest appearance of unengorged trombiculids on Chiroptera was in July, with a tendency to shift the onset of appearance to late July/early August, depending on the host species. The highest total number of larvae collected was in autumn, which was related to the higher number of hosts caught due to bats swarming (Fig. 2). At that time the larvae were collected from 10 bat species, only not from M. alcathoe. In winter, with a limited collection of larvae from hosts during hibernation, bats with larvae were observed under non-used bridges, in tunnels, on rock shelfs, cave ceilings and walls, located close to the entrance of hibernacula. In March and April, at the increasing activity of bats, associated with their emergence from hibernation roosts, larvae were recorded on B. barbastellus, M. brandtii, M. daubentonii, M. myotis, M. nattereri, $P$. auritus, $P$. austriacus, and $R$. hipposideros. In bats caught in places more remote from hibernacula, a lower number of larvae was observed compared to those stated on hosts just emerging from roosts. Only one infested specimen of $M$. 


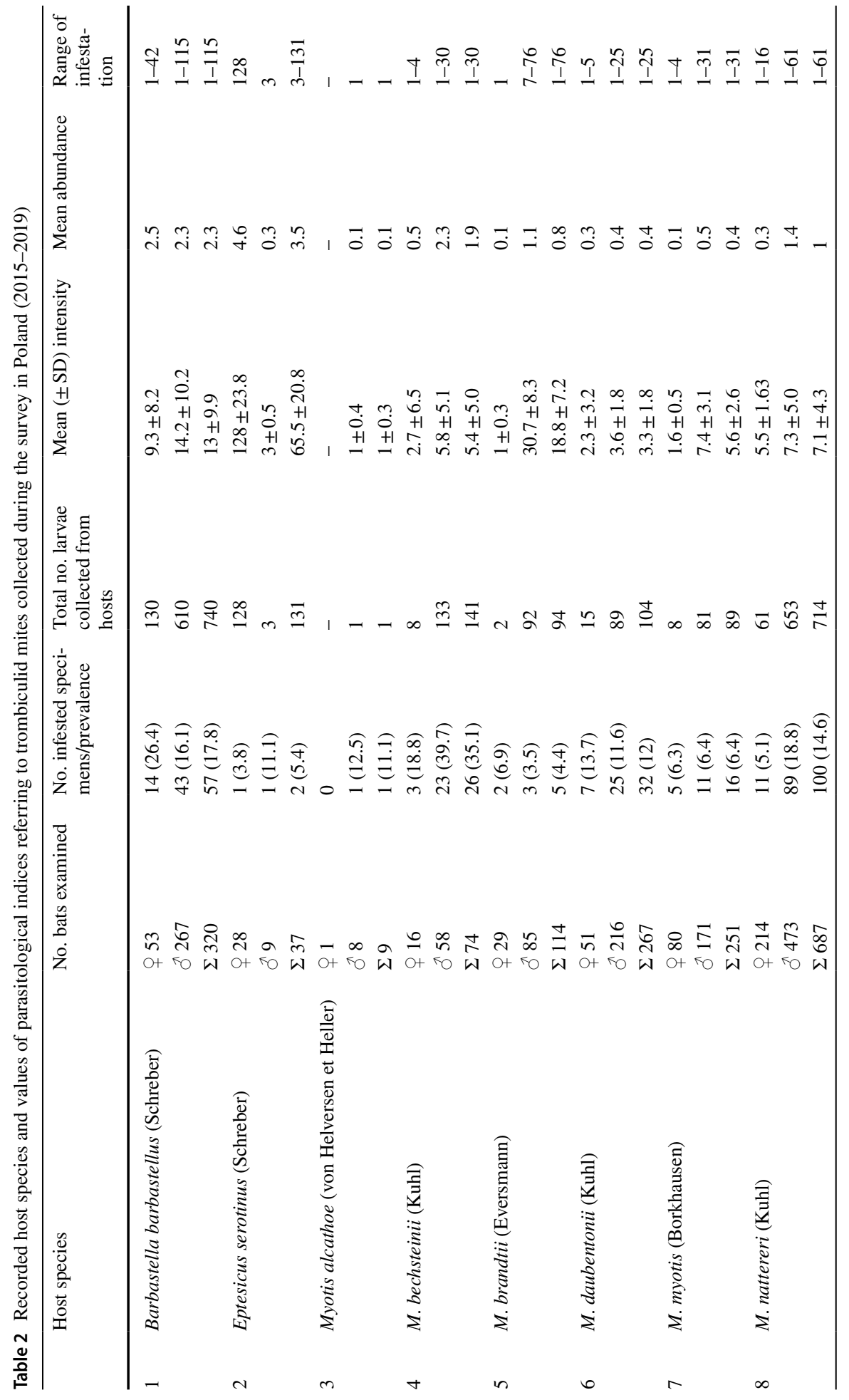




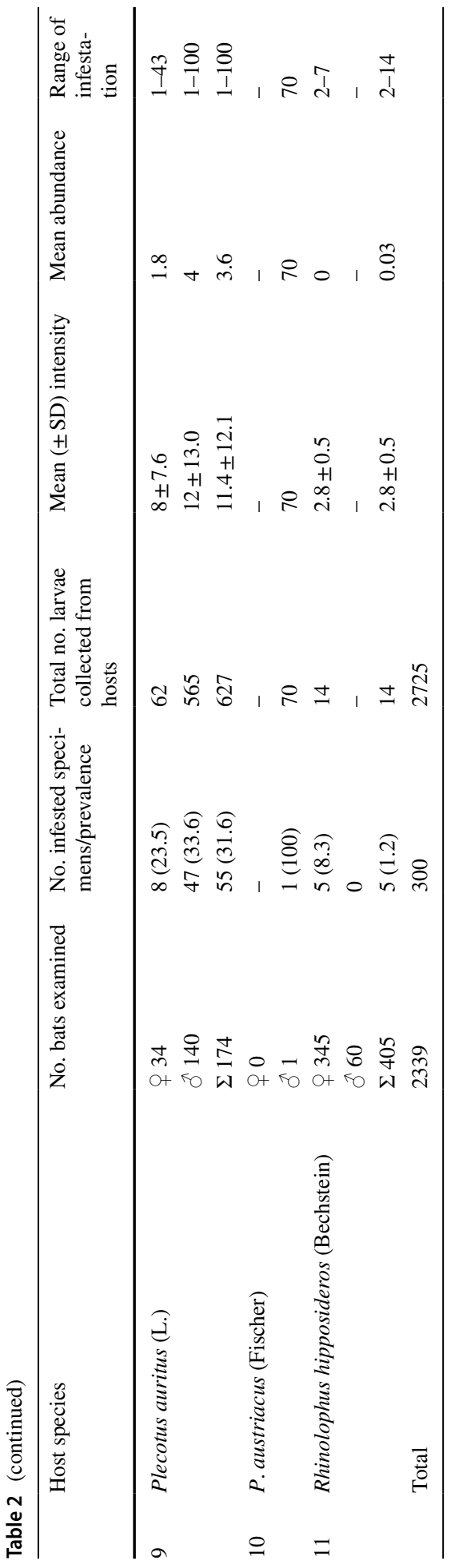




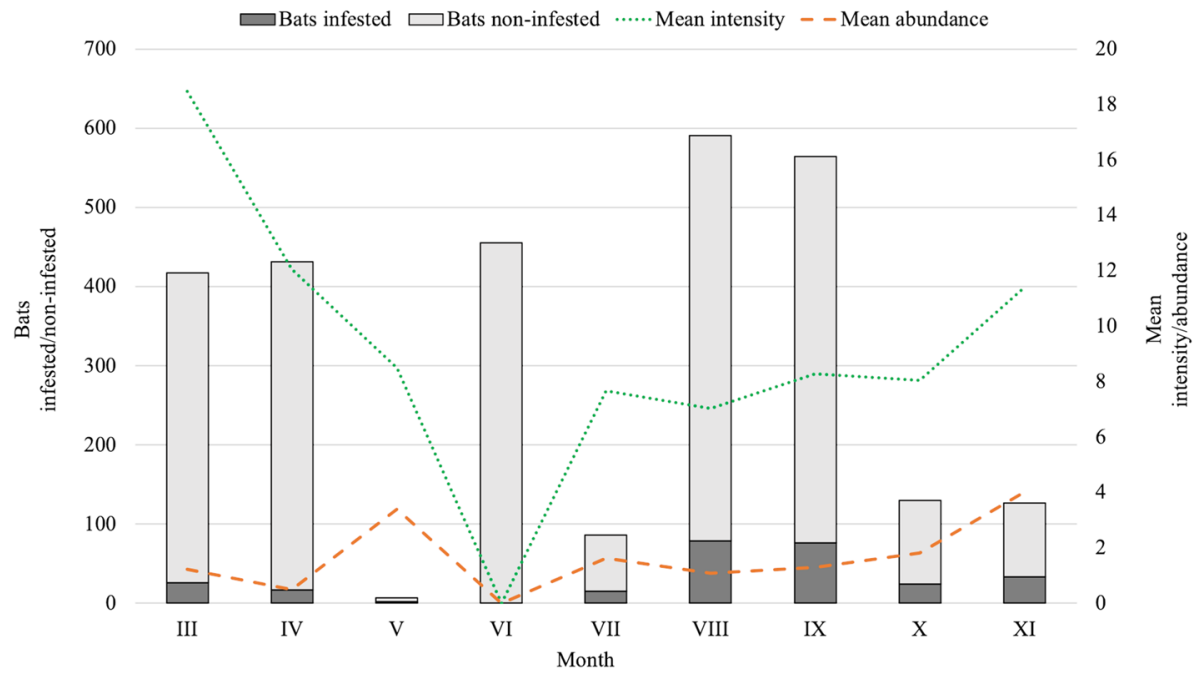

Fig. 2 Trends in seasonal occurrence of chigger-infested bats in Poland. Data cumulated for the years 20152019, excluding the period of bat hibernation, between December and February

alcathoe was caught in mid-April in a park (recreational area). A remarkable decrease in the number of larvae was observed in the mid- and late spring (Fig. 2). In May larvae were observed on only two specimens of $M$. nattereri, in a mountainous locality in southern Poland, with lower temperatures recorded compared to other study areas. In the late spring and in summer, during the recurrent check of bat boxes and maternity roosts occupied by M. nattereri, P. pipistrellus, P. nathusii, $N$. noctula and $R$. hipposideros, the absence of larvae on these hosts was confirmed.

\section{Location of larvae on hosts' body}

The larvae were observed exclusively on the heads of hosts, including on the edges of earlobes, on tragi, and around the eyes, mouth, and nasal opening. The mites tended to form clusters on sparsely haired areas on the ears, whereas only single specimens were observed on the eyes, lips and nasal areas. The overall level of engorgement of chiggers was lower within clusters, in comparison with individuals that parasitized at a distance from each other. There was some variation among host species with regard to which parts of the ears had the most mite larvae. On B. barbastellus the larvae were aggregated at the edge of the earlobes and within the Henry's pocket (cutaneous marginal pouch of the ear); on M. bechsteinii they were found on the inner and outer side of the earlobe; and on P. auritus and on the only specimen of $P$. austriacus caught during the survey they were at the edge of earlobes and on the tragi.

\section{Species identity of bat-associated chiggers}

Based on morphological analyses, all larval trombiculids we examined belonged to the genus Leptotrombidium. Ten percent of specimens represented L. russicum. For other 
examined specimens the character states went beyond the variability known for L. russicum. Due to the mosaic distribution of diagnostic morphological traits, compared to the data on hitherto known members of the genus, the identification of these specimens to species level was not possible.

The ASAP analyses of COI sequences from GenBank and eight specimens that we sequenced ourselves $(n=30$ sequences in total, alignment length $540 \mathrm{bp})$ indicated the occurrence of 17 potential groups/species within Leptotrombidium (see \# symbols in Fig. 4) (asap-score $=2 ; P=0.20, W=0.0112$ ), with the threshold distance $\left(d_{T}\right) 4.6 \%$. The barcode gap within Leptotrombidium revealed a p-distance between groups/species, ranging from 7 to $13 \%$ (Fig. 3). The sequences obtained from trombiculids collected in Poland were assigned to four independent groups. Group \#3 contained three sequences (Fig. 4): OL619429 (obtained from larva collected from B. barbastellus), OL619430 and OL619431 (obtained from deutonymphs collected at the same daily roost). Group \#13 also contained three sequences (Fig. 4): OL619433 (obtained under laboratory conditions from deutonymph which emerged from larva collected from $M$. nattereri), OL619434, OL619435 (obtained from larvae collected from $M$. bechsteinii and $M$. daubentonii, respectively). These groups correspond to the specimens assigned to $L$. russicum and to Leptotrombidium sp. 1, respectively, based on morphological criteria. Two other groups (Fig. 4; groups \#4 and \#2) contained one sequence each, OL619436 (from larva ex M. nattereri) and OL619432 (obtained, under laboratory conditions, from deutonymph which emerged from larva collected from B. barbastellus), identified as Leptotrombidium sp. 2 and Leptotrombidium sp. 3.

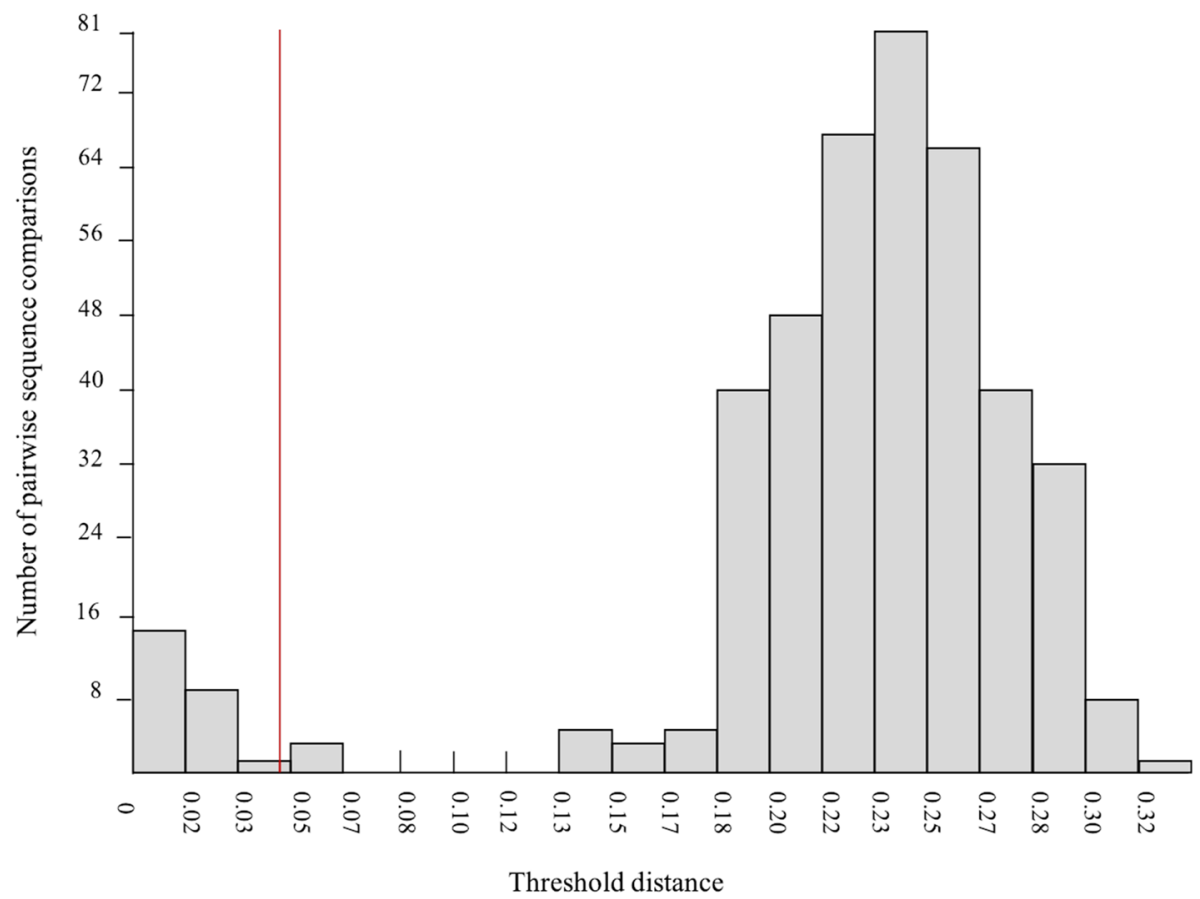

Fig. 3 Distribution of K2P pairwise distances revealed by ASAP. Red line denotes threshold value of intraspecific divergence. (Color figure online) 


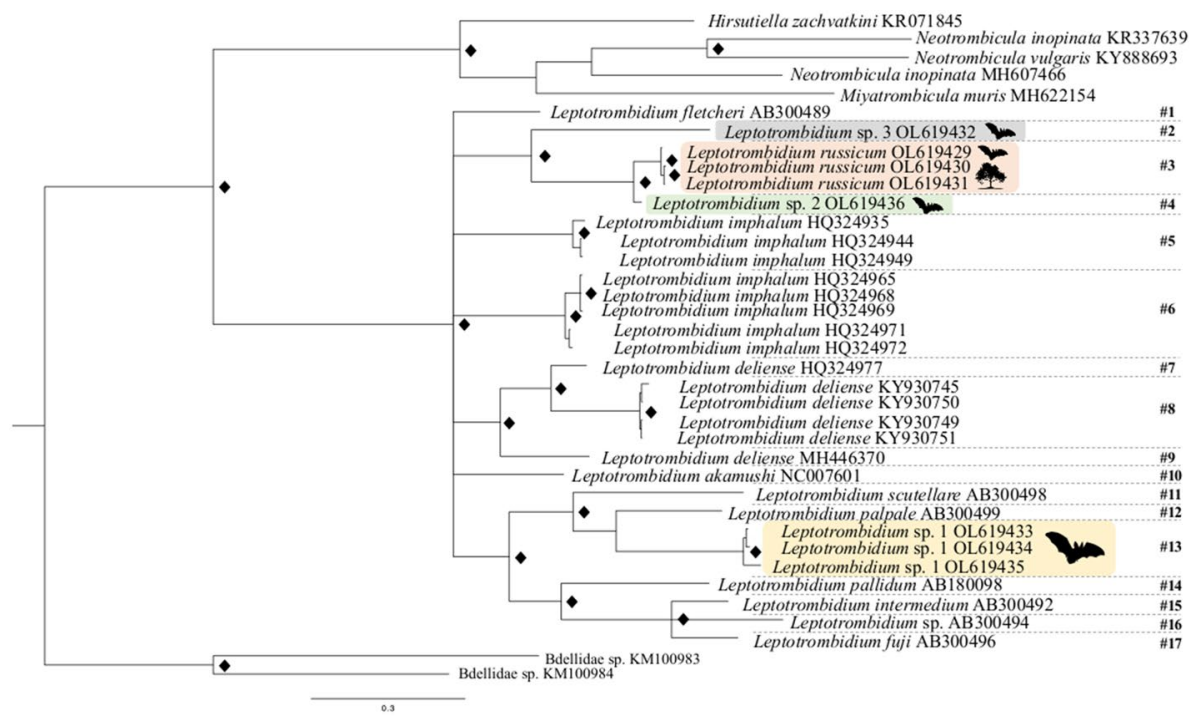

Fig. 4 Phylogenetic tree (Bayesian inference, BI) based on COI dataset. Diamond symbols refer to Bayesian posterior probability (PP) of $>90 \%$. Bat pictograms reflect cases in which larvae were collected from hosts, tree pictograms cases in which deutonymphs were collected from daily roost. Hash symbols (\#) with numbers denote groups obtained using the ASAP method

\section{Phylogenetic relationships}

The BI phylogenetic tree (Fig. 4) corresponded with the results of ASAP. All branches received a high BI support. L. russicum, Leptotrombidium sp. 2 and Leptotrombidium sp. 3 formed a sub-clade separate from Leptotrombidium sp. 1. The genetic within-clade distance recorded for $L$. russicum was $0-1 \%$. The genetic distance between the sequences of L. russicum and Leptotrombidium sp. 2 was 5.6-5.9\%, between L. russicum and Leptotrombidium sp. 3 it was $27.6-28 \%$, whereas the highest distance, $27.6-31 \%$, was recorded between $L$. russicum and Leptotrombidium sp. 1, the latter revealing the sister relations with L. palpale.

\section{Discussion}

Parasitism by trombiculid larvae was confirmed during our survey for the nine species of bats previously recorded as hosts of chiggers in Poland. In addition, the presence of chiggers on Myotis myotis constituted the first country record for this chigger-bat association, whereas a discovery of one larva on M. alcathoe, was the first observed case of this association in the world. Chiggers were not observed on eight of the bat species that were surveyed, of which M. emarginatus and Pipistrellus nathusii have never been recorded as hosts of Trombiculidae.

The different biology and ecology of the host species may translate into different abundance and different intensity and preferences of parasite towards the host's sex (Marshall 
1982; Freeland 1983; Hawlena et al. 2006; Krasnov et al. 2012). Chiroptera species associated with the forest ecosystem and most frequently infested by Leptotrombidium larvae were $B$. barbastellus, $M$. nattereri and $P$. auritus. These species start late summer/autumn activity relatively early (compared to other bat species) and have a varied number of activity peaks during swarming (Ignaczak et al. 2019) which indicates the potential opportunity created for larvae to infest the host at that time.

Our research revealed a male bias in bat-associated Trombiculidae. Previous reports of male-biased parasitism by bat-associated chiggers have been limited to few sources (Jones 1998; Poissant and Broders 2008). The results of studies on bat parasites (other than Trombiculidae) indicate a female-biased infestation (Marshall 1982; Schalk and Forbes 1997; Komeno and Linhares 1999; Chilton et al. 2000; Morales-Montor et al. 2004; Zahn and Rupp 2004; Lučan 2006; Christe et al. 2007; Frank et al. 2015; Postawa and Nagy 2016), whereas only a few studies indicate higher infestation in males (Moore and Wilson 2002; Morand et al. 2004; Sponchiado et al. 2015) or no correlation between the sex and the level of infestation (Moura et al. 2003; Czenze and Broders 2011). Frequent changes of roosts, solitary lifestyle, grooming, and the immune system seem to be of key importance in explaining the relatively low infestation of male bats with ectoparasites from various taxa (Kunz 1976; Moore 2013). On the other hand, the tendency to riskier behaviors in males (Schmid-Hempel 2011) may predict greater susceptibility to parasites (higher infestation), as stated for various mammalian hosts (Krasnov et al. 2012; Oliver-Guimerá et al. 2017).

The patterns of abundance and infestation are strictly associated with the complex life cycle and phenology of chiggers. The evolutionary relationships of trombiculid larvae with vertebrates, unlike most arthropod-associated Parasitengona, facilitated modifications in the phenology of species in a temperate zone, expressed in an extended time of larval appearance through prolonged contact with the host at unfavorable conditions. The highest number of larvae observed in this study at the turn of summer and autumn corresponds to the results of studies carried out on rodents in Poland (Moniuszko et al. 2015, 2017; Moniuszko and Mąkol 2016) and in Slovakia (Daniel 1961). The presence of larvae on bats in winter and in early spring, followed by the decrease in the number later in spring, indicates a gradual abandonment of the hosts at the time of transformation of chiggers from larvae to deutonymphs, until the complete absence of parasites, usually recorded in May.

Parasitic larvae were observed on bat species that most likely prefer places with dynamic microclimate during hibernation. While staying closer to the exit holes, the members of these species receive faster signals related to the increase in temperature outside the caves, which results also in an increase in body temperature and accelerates the termination of hibernation. The onset of bats' activity is probably a factor that stimulates the activity of the larvae. The latter seems to be consistent with slight shift of this phenomenon in time, observed in larvae found on individuals hibernating in the deeper parts of the wintering places, with a more stable microclimate.

The data on chiggers' tendencies to attach to particular parts of the bat's body are inconsistently reported and limited to side information in works devoted to other issues (Domrow 1962; Vercammen-Grandjean 1963; Brown 1997). We could observe that larvae generally attached to areas with limited hair cover, facilitating easy access to the skin. Specimens parasitizing individually or in small clusters were more engorged than those forming the larger clusters. The latter corroborates Goff's (1982) observations on rodentassociated chiggers. The parts of the bats' body occupied by the members of Leptotrombidium were analogous to those listed by Vercammen-Grandjean (1963), Harmata (1967), Haitlinger (1979), and Kalúz and Ševčík (2014). Variation among host species in the specific locations where the larvae attached to the host's ears may result from the different 
structures of the ears (shape, thickness, length, presence, or absence of a tragus) in different bat species. Traub and Wisseman (1974), Goff (1979), and Barnard et al. (2015) considered the host species as the main factor determining the anatomical site preferences of larvae. According to these authors, the grooming behavior, in the case of bats, consisting of licking and scratching (Zhang et al. 2013), may have a direct impact on the area where parasites are observed.

The gradual increase in species richness towards tropical latitudes is not directly reflected in the number of trombiculid species recorded from Central European countries, which is due to the uneven state of knowledge of the chigger fauna and the still unstable status of species separated based on the morphological characters. All specimens subjected to detailed morphological analyses in this study were assigned to Leptotrombidium. The genus comprises 342 named species worldwide, of which 23 are associated with Chiroptera (Stekolnikov 2013). Of those, only L. russicum has been previously recorded from Central Europe (Zajkowska et al. 2018). Our research indicated the presence of L. russicum on bats in Poland, and in addition, the presence of at least three other species within the same genus. The representatives of Oudemansidium were not confirmed in the examined material. This genus-with about 10 nominal species, two of which (O. musca and $O$. komareki) were reported from Central Europe-is considered as associated only with bats (Shatrov and Kudryashova 2008; Stekolnikov 2018). The absence of $O$. musca, previously collected from bats in Poland (Haitlinger and Ruprecht 1985; Haitlinger 1979; Haitlinger and Łupicki 2008) may indicate an accidental occurrence of this species in the country. Misidentification of Oudemansidium and Leptotrombidium can be excluded due to clear morphological differences between the members of these genera.

Our study revealed a lack of consistency between the morphological and molecular criteria for species discrimination in Trombiculidae. The current taxonomy of chiggers is based on morphology. Discrepancies in the selection of key characters and character states in identification keys constructed by different authors (Kudryashova 1998; Fernandes and Kulkarni 2003; Stekolnikov 2013) often lead to ambiguous decisions which may result in misidentification. With the priority given to quantitative traits - total number of dorsal and ventral setae (NDV), index pedibus (IP) - in species diagnoses, verification of the material based solely on these features is often insufficient to sanction species distinctness. The strategies of host selection, in which the habitat plays a crucial role in the formation of interactions (Peng et al. 2018; Lv et al. 2019), seem to differ from those observed in other representatives of terrestrial Parasitengona. Moreover, the host-associated differences in morphological traits (Moniuszko et al. 2015) at a relatively wide host spectrum, confirm the existence of various evolutionary modes among morphological traits in Trombiculidae. Thus, correct identification of trombiculid species, also influencing the inference about the host spectrum and host specificity, is not possible without referring to criteria beyond the currently employed morphological ones. Species delimitation through an integrative approach to taxonomy constitutes a solution in studies on Trombiculidae. Attention should be paid to the potential presence of cryptic species confirmed in other systematic groups of mites (de Rojas et al. 2002; Navia et al. 2013; Doña et al. 2015; Low et al. 2015). Use of non-morphological criteria in species discrimination of chiggers has been rare up to now. Korkusol et al. (2010) tried to develop a molecular taxonomic key for the precise identification of trombiculid mites using the COI gene; the results obtained for the deduced amino acid sequence of full-length COI revealed a surprising amount of variation for species identified earlier based on a morphological criterion. It is noteworthy, that the scale of genetic differences, also observed in this study, is not universal. Intraspecific variability for selected species of insects, spiders, and mites, as a rule, does not exceed 3.6\%, whereas 
interspecific variability is in the range of 2.3-29.9\% (Anderson and Morgan 2007; Dabert et al. 2008; Skoracka and Dabert 2010; Iftikhar et al. 2016; Mąkol et al. 2019). In the present study, the intraspecific variation threshold in Trombiculidae attained $4.6 \%$. The value of interspecific distance ( $>20 \%$ ) may, however, pose a question on the common generic identity of putative species examined in the present survey.

Our research reveals several still open issues and problems related to the taxonomy, ecology, and biology of Trombiculidae, with special reference to interaction of chiggers with their host, and implies the need for deeper insight into this family, with the application of hitherto neglected tools.

Acknowledgements We thank all chiropterologists whose help in the field collection of bats would be difficult to overestimate, especially Tomasz Postawa (Institute of Systematics and Evolution of Animals, Polish Academy of Sciences, Kraków), Maurycy Ignaczak (The Polish Society for the Protection of Bats (OTON)), Paweł and Anna Kmiecik. Our thanks go to all friends whose company in the field had an influence on the final shape of this work. We are grateful to Alexandr A. Stekolnikov, Andreas Wohltmann, and one anonymous reviewer, for helpful discussion and comments that greatly improved this manuscript.

Author contributions PZ: collection and preparation of the material, data analysis, writing the manuscript; JM: conceptualization, supervision and writing the manuscript. Both authors have read and approved the final version of the manuscript.

Funding Statutory subsidy granted by the Ministry of Education and Science in Poland.

Data availability Data supporting the conclusions of this article are included in the article.

Code availability Sequences used in this study are deposited in the GenBank database under the accession numbers: OL619429, OL619430, OL619431, OL619432, OL619433, OL619434, OL619435 and OL619436.

\section{Declarations}

Conflict of interest All authors declared that there is no conflict of interest.

Ethical approval Not applicable.

Consent to participate Not applicable.

Consent for publication Not applicable.

Open Access This article is licensed under a Creative Commons Attribution 4.0 International License, which permits use, sharing, adaptation, distribution and reproduction in any medium or format, as long as you give appropriate credit to the original author(s) and the source, provide a link to the Creative Commons licence, and indicate if changes were made. The images or other third party material in this article are included in the article's Creative Commons licence, unless indicated otherwise in a credit line to the material. If material is not included in the article's Creative Commons licence and your intended use is not permitted by statutory regulation or exceeds the permitted use, you will need to obtain permission directly from the copyright holder. To view a copy of this licence, visit http://creativecommons.org/licenses/by/4.0/.

\section{References}

Anderson DL, Morgan MJ (2007) Genetic and morphological variation of bee-parasitic Tropilaelaps mites (Acari: Laelapidae): new and redefined species. Exp Appl Acarol 43:1-24. https://doi.org/10.1007/ s10493-007-9103-0 
Barnard K, Krasnov BR, Goff L, Matthee S (2015) Infracommunity dynamics of chiggers (Trombiculidae) parasitic on a rodent. Parasitology 142:1605-1611. https://doi.org/10.1017/S0031182015001110

Bassini-Silva R, Huang-Bastos M, Welbourn C, Ochoa R, Barros-Battesti DM, de Castro JF (2021) A new genus of chiggers (Trombidiformes: Trombiculidae) from bats in Jamaica. Acta Parasit. https://doi. org/10.1007/s11686-021-00336-0

Bernard R, Felska M, Mąkol J (2019) Erythraeid larvae parasitizing dragonflies in Zambia-description of Leptus (Leptus) chingombensis sp. Nov. with data on biology and ecology of host-parasite interactions. Syst Appl Acarol 24:790-813. https://doi.org/10.11158/saa.24.5.6

Brown WA (1997) Ten new species of chiggers (Acari: Trombiculidae) from bat hosts from the Philippines. Int J Acarol 23:147-166. https://doi.org/10.1080/01647959708683558

Bush AO, Lafferty KD, Lotz JM, Shostak AW (1997) Parasitology meets ecology on its own terms: Margolis et al. revisited. J Parasitol 83:575-583. https://doi.org/10.2307/3284227

Caputo V, Santi F, Cascio A, Trizzino M, Colomba C (2018) Trombiculiasis: an underreported ectoparasitosis in Sicily. Infez Med 1:77-80

Chilton G, Vonhof MJ, Peterson BV, Wilson N (2000) Ectoparasitic insects of bats in British Columbia, Canada. J Parasitol 86:191-192. https://doi.org/10.1645/0022-3395(2000)086[0191:EIOBIB]2.0. $\mathrm{CO} ; 2$

Christe P, Glaizot O, Evanno G, Bruyndonckx N, Devevey G, Yannic G, Patthey P, Maeder A, Vogel P, Arlettaz R (2007) Host sex and ectoparasites choice: preference for, and higher survival on female hosts. J Anim Ecol 76:703-710. https://doi.org/10.1111/j.1365-2656.2007.01255.x

Crossley DA Jr (1960) Comparative external morphology and taxonomy of nymphs of the Trombiculidae (Acarina). Univ Kans Sci Bull 40:135-321

Cruickshank RH (2002) Molecular markers for the phylogenetics of mites and ticks. Syst Appl Acarol 7:314. https://doi.org/10.11158/saa.7.1.1

Czenze ZJ, Broders HG (2011) Ectoparasite community structure of two bats (Myotis lucifugus and M. septentrionalis) from the Maritimes of Canada. J Parasitol Res. https://doi.org/10.1155/2011/341535

Dabert J, Ehrnsberger R, Dabert M (2008) Glaucalges tytonis sp. n. (Analgoidea, Xolalgidae) from the barn owl Tyto alba (Strigiformes, Tytonidae): compiling morphology with DNA barcode data for taxon descriptions in mites (Acari). Zootaxa 1719:41-52. https://doi.org/10.11646/zootaxa.1719.1.2

Dabert M, Proctor H, Dabert J (2016) Higher-level molecular phylogeny of the water mites (Acariformes: Prostigmata: Parasitengonina: Hydrachnidiae). Mol Phylogenet Evol 101:75-90. https://doi.org/10. 1016/j.ympev.2016.05.004

Daniel M (1961) Contribution a la connaissance des formes adultes des trombiculidae d'Europe. I. Description des nymphes et des adultes du Trombicula (N.) zachvatkini Shluger 1948 et Trombicula (N.) talmiensis Shluger 1955. Acarologia 3:24-47

de Rojas M, Mora MD, Úbeda JM, Cutillas C, Navajas M, Guevara DC (2002) Phylogenetic relationships in rhinonyssid mites (Acari: Rhinonyssidae) based on ribosomal DNA sequences: insights for the discrimination of closely related species. Parasitol Res 88:675-681. https://doi.org/10.1007/ s00436-002-0647-y

Dietz C, von Helversen O (2004) Illustrated identification key to the bats of Europe. Electronic publication, ver. 1.0. 2004. https://www.researchgate.net/publication/228985859_Illustrated_identification_key_ to_the_bats_of_Europe. Accessed 13 April 2021

Domrow R (1962) Seven new Oriental-Australian chiggers (Acarina, Trombiculidae). Treubia 26:39-56

Doña J, Díaz-Real J, Mironov S, Bazaga P, Serrano D, Jovani R (2015) DNA barcoding and minibarcoding as a powerful tool for feather mite studies. Mol Ecol Resour 15:1216-1225. https://doi.org/10.1111/ 1755-0998.12384

Felska M, Wohltmann A, Mąkol J (2018) A synopsis of host-parasite associations between Trombidioidea (Trombidiformes: Prostigmata, Parasitengona) and arthropod hosts. Syst Appl Acarol 23:1375-1479. https://doi.org/10.11158/saa.23.7.14

Fernandes SJS, Kulkarni SM (2003) Studies on the trombiculid mite fauna of India. Records of the Zoological Survey of India. Occasional Paper 212

Frank R, Kuhn T, Werblow A, Liston A, Kochmann J, Klimpel S (2015) Parasite diversity of European Myotis species with special emphasis on Myotis myotis (Microchiroptera, Vespertilionidae) from a typical nursery roost. Parasite Vector 8:101. https://doi.org/10.1186/s13071-015-0707-7

Freeland WJ (1983) Parasites and the coexistence of animal host species. Am Nat 121:223-236. https://doi. org/10.1086/284052

Goff ML (1979) Host exploitation by chiggers (Acari: Trombiculidae) infesting Papua New Guinea land mammals. Pac Insects 20:321-353 
Goff ML (1982) New Guinea chiggers (Acari: Trombiculidae). In: Gressitt JL (ed) Biogeography and ecology of New Guinea, vol 42. Springer, Dordrecht, pp 545-555. https://doi.org/10.1007/978-94-0098632-9_25

Haitlinger R (1979) Pasożyty zewnętrzne nietoperzy Dolnego Śląska, V Trombidiformes, Sarcoptiformes (Acarina). Wiad Parazytol 25:105-117

Haitlinger R, Łupicki D (2008) Arthropods (Acari, Siphonaptera, Heteroptera, Psocoptera) associated with Nyctalus noctula (Schreber, 1774) (Chiroptera: Vespertilionidae) in Southern Poland. Wiad Parazytol 54:123-130

Haitlinger R, Ruprecht L (1977) Przyczynek do fauny pasożytów zewnętrznych nietoperzy Puszczy Białowieskiej. Prz Zool 21:332-334

Haitlinger R, Ruprecht L (1985) Stawonogi zebrane na nietoperzach z Kujaw (Acari i Siphonaptera). Pol Pismo Entomol 55:615-618

Haitlinger R, Ruprecht L (1992) Parasitic arthropods (Siphonaptera, Diptera, Acari) of bats from western part of the Białowieża Primeval Forest. Nyctalus 3:315-319

Harmata W (1967) Występowanie Trombicula (Leptotrombidium) russica Oudemans 1902 (Acarina, Trombiculidae) na nietoperzach mopkach, Barbastella barbastellus (Schreber, 1774). Wiad Parazytol $13: 267-270$

Hawlena H, Abramsky Z, Krasnov BR (2006) Ectoparasites and age-dependent survival in a desert rodent. Oecologia 148:30-39. https://doi.org/10.1007/s00442-005-0345-4

Iftikhar R, Ashfaq M, Rasool A, Hebert PDN (2016) DNA barcode analysis of thrips (Thysanoptera) diversity in Pakistan reveals cryptic species complexes. PLoS ONE 11:e0146014. https://doi.org/10.1371/ journal.pone. 0146014

Ignaczak M, Postawa T, Lesiński G, Gottfried I (2019) The role of autumnal swarming behavior and ambient air temperature in the variation of body mass in temperate bat species. Hystrix It J Mamm 30:6573. https://doi.org/10.4404/hystrix-00104-2018

Jones J (1998) Occurrence and abundance of chiggers (Acari: Trombiculidae) on bats (Chiroptera: Vespertilionidae) in eastern Ontario. Can Field-Nat 112:230-233

Kalúz S, Ševčík M (2014) A new species of the genus Grandjeana (Koçak \& Kemal, 2009) (Acari: Trombiculidae) from Mauritanian bat with a key to species of the genus. Int J Acarol 40:31-36. https://doi. org/10.1080/01647954.2013.875063

Kalúz S, Šrámek P, Ševčík M (2021) Rudnicula goffi n. sp. (Acariformes: Trombiculidae) from the diadem leaf-nosed bat Hipposideros diadema (Geoffroy) (Chiroptera: Hipposideridae) on Bali. Indonesia Syst Parasitol 98:17-24. https://doi.org/10.1007/s11230-020-09958-w

Kaya TI, Yilmaz MA (2019) Dermoscopy confirmed Trombiculidae larva infestation in Turkey. Int J Dermatol 58:e120-e121. https://doi.org/10.1111/ijd.14433

Kearse M, Moir R, Wilson A, Stones-Havas S, Cheung M, Sturrock S, Buxton S, Cooper A, Markowitz S, Duran C, Thierer T, Ashton B, Meintjes P, Drummond A (2012) Geneious Basic: An integrated and extendable desktop software platform for the organization and analysis of sequence data. Bioinformatics 28:1647-1649. https://doi.org/10.1093/bioinformatics/bts199

Kepka O (1959) Die Nymphe von Trombicula (Leptotrombidium) russica Oudms. 1902 (Acari: Fam. Trombiculidae). Z Parasitenkd 19:315-321. https://doi.org/10.1007/BF00260218

Kimura M (1980) A simple method for estimating evolutionary rates of base substitutions through comparative studies of nucleotide sequences. J Mol Evol 16:111-120. https://doi.org/10.1007/BF01731581

Komeno CA, Linhares AX (1999) Batflies parasitic on some phyllostomid bats in Southeastern Brazil: parasitism rates and host-parasite relationships. Mem Inst Oswaldo Cruz 94:131-136. https://doi.org/10. 1590/S0074-02761999000200004

Korkusol A, Takhampunya R, Monkanna T, Khlaimanee N, Evans E, Richardson J (2010) Development of a molecular taxonomic key for the identification of scrub typhus vectors, mites within the genus Leptotrombidium. Abstract Book, American Society of Tropical Medicine and Hygiene, 59th Annual Meeting. A J Trop Med Hyg 83(5):61

Krasnov BR, Bordes F, Khokhlova IS, Morand S (2012) Gender-biased parasitism in small mammals: patterns, mechanisms, consequences. Mammalia 76:1-13. https://doi.org/10.1515/mammalia-2011-0108

Kudryashova NI (1998) Chigger mites (Acariformes, Trombiculidae) of East Palearctics. KMK Scientific Press, Moscow ([in Russian])

Kumlert R, Chaisiri K, Anantatat T, Stekolnikov AA, Morand S, Prasartvit A, Makepeace BL, Sungvornyothin S, Paris DH (2018) Autofluorescence microscopy for paired-matched morphological and molecular identification of individual chigger mites (Acari: Trombiculidae), the vectors of scrub typhus. PLoS ONE 13:e0193163. https://doi.org/10.1371/journal.pone.0193163

Kunz TH (1976) Observations on the winter ecology of the batfly Trichobius corynorhini Cockerell (Diptera: Streblidae). J Med Entomol 12:631-636. https://doi.org/10.1093/jmedent/12.6.631 
Liu D, Yi T-C, Xu Y, Zhang Z-Q (2013) Hotspots of new species discovery: new mite species described during 2007 to 2012. Zootaxa 3663:1-102. https://doi.org/10.11646/zootaxa.3663.1.1

Low VL, Tay ST, Kho KL, Koh FX, Tan TK, Lim YAL, Ong BL, Panchadcharam C, Norma-Rashid Y, Sofian-Azirun M (2015) Molecular characterization of the tick Rhipicephalus microplus in Malaysia: new insights into the cryptic diversity and distinct genetic assembalges throughout the world. Parasites Vectors 8:341. https://doi.org/10.1186/s13071-015-0956-5

Lučan R (2006) Relationships between the parasitic mite Spinturnix andegavinus (Acari: Spinturnicidae) and its bat host, Myotis daubentoniii (Chiroptera: Vespertilionidae): seasonal, sex- and age-related variation in infestation and possible impact of the parasite on the host condition and roosting behaviour. Folia Parasitol 53:147-152. https://doi.org/10.14411/fp.2006.019

Lv Y, Guo X-G, Jin D-C, Song W, Fan R, Zhao C, Zhang Z, Mao K, Peng P, Lin H, Zhao Y, Qian T, Dong W (2019) Host selection and seasonal fluctuation of Leptotrombidium deliense (Walch, 1922) (Trombidiformes: Trombiculidae) at a localized area of southern Yunnan, China. Syst Appl Acarol 24:2253-2271. https://doi.org/10.11158/saa.24.11.15

Mąkol J, Cichocki J, Felska M, Kłosińska A, Łaydanowicz J, Łupicki D, Gabryś G (2010) A new data on biology and taxonomy of Neotrombicula inopinata (Oudemans, 1909) and Leptotrombidium russicum (Oudemans, 1902) (Acari: Actinotrichida: Trombiculidae). Ann Zool 60:419-427. https://doi.org/10. 3161/000345410X535406

Mąkol J, Saboori A, Felska M (2019) Inter- and intraspecific variability of morphological and molecular characters in Allothrombium species, with special reference to Allothrombium fuliginosum. Exp Appl Acarol 78:485-504. https://doi.org/10.1007/s10493-019-00400-5

Marshall AG (1982) Ecology of insects ectoparasitic on bats. In: Kunz TH (ed) Ecology of Bats. Springer, Boston, pp 369-401. https://doi.org/10.1007/978-1-4613-3421-7_10

Moniuszko H, Mąkol J (2014) Chigger mites (Actinotrichida: Parasitengona, Trombiculidae) of Poland. An updated distribution and hosts. Ann Parasitol 60:103-117

Moniuszko H, Mąkol J (2016) Host-parasite association in trombiculid mites (Actinotrichida: Trombiculidae) of temperate zone - the case of Hirsutiella zachvatkini (Schluger, 1948); are we dealing with prolonged contact with the host? Parasites Vectors 9:61. https://doi.org/10.1186/s13071-016-1339-2

Moniuszko H, Zaleśny G, Mąkol J (2015) Host-associated differences in morphometric traits of parasitic larvae Hirsutiella zachvatkini (Actinotrichida: Trombiculidae). Exp Appl Acarol 67:123-133. https:// doi.org/10.1007/s10493-015-9925-0

Moniuszko H, Shatrov AB, Mąkol J (2017) Description of active postlarval forms of Neotrombicula vulgaris (Schluger, 1955) (Prostigmata: Trombiculidae), with notes on biology and ecology of the species. Ann Zool 67:243-251. https://doi.org/10.3161/00034541ANZ2017.67.2.005

Moniuszko H, Felska M, Mąkol J (2018) Evidence for co-invasion events: different chigger species (Actinotrichida, Trombidioidea: Trombiculidae) share a host. Exp Appl Acarol 1:29-39. https://doi.org/10. 1007/s10493-018-0293-4

Moore J (2013) An overview of parasite-induced behavioral alterations — and some lessons from bats. J Exp Biol 216:11-17. https://doi.org/10.1242/jeb.074088

Moore SL, Wilson K (2002) Parasites as a viability cost of sexual selection in natural populations of mammals. Science 297:2015-2018. https://doi.org/10.1126/science.1074196

Morales-Montor J, Chavarria A, De León MA, Del Castillo LI, Escobedo EG, Sánchez EN, Vargas JA, Hernández-Flores M, Romo-González T, Larralde C (2004) Host gender in parasitic infections of mammals: an evaluation of the female host supremacy paradigm. J Parasitol 90:531-546. https://doi. org/10.1645/GE-113R3

Morand S, Goüy de Bellocq J, Stanko M, Miklisová YD (2004) Is sex-biased ectoparasitism related to sexual size dimorphism in small mammals of Central Europe? Parasitology 129:505-510. https://doi.org/ $10.1017 / \mathrm{S} 0031182004005840$

Moura MO, Bordignon MO, Graciolli G (2003) Host characteristics do not affect community structure of ectoparasites on the fishing bat Noctilio leporinus (L., 1758) (Mammalia: Chiroptera). Mem Inst Oswaldo Cruz 98:811-815. https://doi.org/10.1590/S0074-02762003000600017

Nadchatram M (2006) A review of endoparasitic acarines of Malaysia with special reference to novel endoparasitism of mites in amphibious sea snakes and supplementary notes on ecology of chiggers. Trop Biomed 23:1-22

Navia D, Mendonça RS, Ferragut F, Miranda LC, Trincado RC, Michaux J, Navajas M (2013) Cryptic diversity in Brevipalpus mites (Acari: Tenuipalpidae). Zool Scr 42:406-426. https://doi.org/10.1111/ zsc. 12013

Nielsen DH, Robbins RG, Rueda LM (2021) Annotated world checklist of the Trombiculidae and Leeuwenhoekiidae (1758-2021) (Acari: Trombiculoidea), with notes on nomenclature, taxonomy and distribution. Zootaxa 4967:1-243. https://doi.org/10.11646/zootaxa.4967.1.1 
Okarma H, Bogdanowicz W, Rychlik L, Zalewski A. Atlas Ssaków Polski. Instytut Ochrony Przyrody PAN. https://www.iop.krakow.pl/Ssaki/gatunki. Accessed 25 June 2021

Oliver-Guimerá A, Martínez-Carrasco C, Tvarijonaviciute A, Ruiz R, de Ybáñez M, Martínez-Guijosa J, López-Olvera JR, Fernández-Aguilar X, Colom-Cadena A, Mentaberre G, Velarde R, Gassó D, Garel M, Rossi L, Lavín S, Serrano E (2017) The physiological cost of male-biased parasitism in a nearly monomorphic mammal. Parasites Vectors 10:200. https://doi.org/10.1186/s13071-017-2060-5

Peng P-Y, Guo X-G, Jin D-C, Dong W-G, Qian T-J, Qin F, Yang Z-H, Fan R (2018) Landscapes with different biodiversity influence distribution of small mammals and their ectoparasitic chigger mites: a comparative study from southwest China. PLoS ONE 13:e0189987. https://doi.org/10.1371/journal. pone.0189987

Piksa K, Gubała WJ (2020) First record of Miniopterus schreibersii (Chiroptera: Miniopteridae) in Polanda possible range expansion? Mamm Res 66:211-215. https://doi.org/10.1007/s13364-020-00533-8

Poissant JA, Broders HG (2008) Ectoparasite prevalence in Myotis lucifugus and M. septentrionalis (Chiroptera: Vespertilionidae) during fall migration at Hayes Cave, Nova Scotia. Northeast Nat 15:515-522. https://doi.org/10.1656/1092-6194-15.4.515

Porco D, Rougerie R, Deharveng L, Hebert P (2010) Coupling non-destructive DNA extraction and voucher retrieval for small soft-bodied Arthropods in a high-throughput context: the example of Collembola. Mol Ecol Resour 10:942-945. https://doi.org/10.1111/j.1755-0998.2010.2839.x

Postawa T, Nagy Z (2016) Variation of parasitism patterns in bats during hibernation: the effect of host species, resources, health status, and hibernation period. Parasitol Res 115:3767-3778. https://doi. org/10.1007/s00436-016-5138-7

Puillandre N, Brouillet S, Achaz G (2021) ASAP: assemble species by automatic partitioning. Mol Ecol Resour 21:609-620. https://doi.org/10.1111/1755-0998.13281

Rambaut A (2018) FigTree. http://tree.bio.ed.ac.uk/software/figtree/. Accessed 13 Aug 2020

Ronquist F, Huelsenbeck JP (2003) MrBayes 3: Bayesian phylogenetic inference under mixed models. Bioinformatics 19:1572-1574. https://doi.org/10.1093/bioinformatics/btg180

Ronquist F, Teslenko M, van der Mark P, Ayres D, Darling A, Höhna S, Larget B, Liu L, Suchard MA, Huelsenbeck JP (2012) MrBayes 3.2: efficient Bayesian phylogenetic inference and model choice across a large model space. Syst Biol 61:539-542. https://doi.org/10.1093/sysbio/sys029

Santibáñez-Sáenz P (2015) Trobicúlidos y trombiculiasis en La Rioja. Dissertation, Universidad de La Rioja. https://dialnet.unirioja.es/servlet/tesis?codigo=46014. Accessed 15 Apr 2021

Schalk G, Forbes MR (1997) Male bias in parasitism of mammals: effects of study type, host age, and parasite taxon. Oikos 78:67-74. https://doi.org/10.2307/3545801

Schmid-Hempel P (2011) Evolutionary parasitology: the integrated study of infections, immunology, ecology, and genetics. Oxford University Press, Oxford. https://doi.org/10.1093/acprof:oso/97801 99229482.001.0001

Ševčík M, Kalúz S, Šrámek P (2021) A new species of Chiroptella Vercammen-Grandjean, 1960 (Acari: Trombiculidae) from diadem leaf-nosed bat Hipposideros diadema (Geoffroy) (Chiroptera: Hipposideridae) in Bali Island (Indonesia) with distribution records, hosts, and a key to the species of the genus. Syst Parasitol 98:1-15. https://doi.org/10.1007/s11230-020-09955-z

Shao R, Mitani H, Barker SC, Takahashi M, Fukunaga M (2005) Novel mitochondrial gene content and gene arrangement indicate illegitimate inter-mtDNA recombination in the chigger mite, Leptotrombidium pallidum. J Mol Evol 60:764-773. https://doi.org/10.1007/s00239-004-0226-1

Shatrov AB, Kudryashova NI (2006) Taxonomy, life cycles and the origin of parasitism in trombiculid mites. In: Morand S, Krasnov BR, Poulin R (eds) Micromammals and Macroparasites. Springer, Tokyo, pp 119-140

Shatrov AB, Kudryashova NI (2008) Taxonomic ranking of major trombiculid subtaxa with remarks on the evolution of host-parasite relationships (Acariformes: Parasitengona: Trombiculidae). Ann Zool 58:279-287. https://doi.org/10.3161/000345408X326591

Skoracka A, Dabert M (2010) The cereal rust mite Abacarus hystrix (Acari: Eriophyoidea) is a complex of species: evidence from mitochondrial and nuclear DNA sequences. Bull Entomol Res 100:263272. https://doi.org/10.1017/S0007485309990216

Sponchiado J, Melo GL, Landulfo G, Jacinavicius FC, Barros-Battesti DM, Cáceres NC (2015) Interaction of ectoparasites (Mesostigmata, Phthiraptera and Siphonaptera) with small mammals in Cerrado fragments, western Brazil. Exp Appl Acarol 66:369-381. https://doi.org/10.1007/ s10493-015-9917-0

Stecher G, Tamura K, Kumar S (2020) Molecular evolutionary genetics analysis (MEGA) for macOS. Mol Biol Evol 37:1237-1239. https://doi.org/10.1093/molbev/msz312

Stekolnikov AA (2013) Leptotrombidium (Acari: Trombiculidae) of the world. Zootaxa 3728:1-173. https://doi.org/10.11646/zootaxa.3728.1.1 
Stekolnikov AA (2018) Taxonomy and distribution of African chiggers (Acariformes, Trombiculidae). Eur J Taxon 395:1-233. https://doi.org/10.5852/ejt.2018.395

Stekolnikov AA, Kar S (2015) A case of domestic goat parasitism by Neotrombicula heptneri (Acariformes: Trombiculidae) in Turkey. Acarologia 55:355-359. https://doi.org/10.1051/acarologia/20152176

Stekolnikov AA, Quetglas J (2019) Bat-infesting chiggers (Acariformes: Trombiculidae) of the Balearic Islands and new data on the genus Trisetica Traub et Evans, 1950. Folia Parasitol 66:017. https:// doi.org/10.14411/fp.2019.017

Stekolnikov AA, Waap H, Gomes J, Antunes T (2016) Chigger mites of the genus Ericotrombidium (Acariformes: Trombiculidae) attacking pets in Europe. Vet Parasitol 221:60-63. https://doi.org/ 10.1016/j.vetpar.2016.03.009

Traub R, Wisseman CL (1974) The ecology of chigger-borne rickettsiosis (scrub typhus). J Med Entomol 11:237-303. https://doi.org/10.1093/jmedent/11.3.237

Vercammen-Grandjean PH (1963) Contribution a l'étude de la faune d'Afghanistan 77. Trombiculidae de chiroptéres. Acarologia 5:582-615

Walter DE, Krantz GW (2009) Collecting, rearing, and preparing specimens. In: Krantz GW, Walter DE (eds) A manual of acarology, 3rd edn. Texas Tech University Press, Lubbock, pp 83-96

Whitaker JO Jr, Ritzi CM, Dick CW (2009) Collecting and preserving bat ectoparasites for ecological study. In: Kunz TH, Parsons S (eds) Ecological and behavioral methods for the study of bats. Johns Hopkins University Press, Baltimore, pp 806-827

Willmann C (1952) Parasitische Milben an Kleinsäugern. Z Parasitenkd 15:392-428. https://doi.org/10. 1007/BF00259346

Wilson DE, Mittermeier RA (2019) Handbook of the Mammals of the World-Volume 9. Lynx Edicions in association with Conservation International and IUCN

Wohltmann A, Köhler J, Martin P (2006) Endoparasitic mite infection of anuran amphibians from Bolivian montane rain forests, with descriptions of two new Hannemania species (Acari: Parasitengona: Trombiculidae: Leeuwenhoekiinae). Org Divers Evol 6:141-150. https://doi.org/10.1016/j.ode.2005. 07.003

Zahn A, Rupp D (2004) Ectoparasite load in European vespertilionid bats. J Zool 262:383-391. https://doi. org/10.1017/S0952836903004722

Zajkowska P, Moniuszko H, Mąkol J (2018) Host-parasite associations between bats (Mammalia: Chiroptera) and chiggers (Trombidiformes: Trombiculidae)—a review and checklist. Ann Zool 68:97-178. https://doi.org/10.3161/00034541ANZ2018.68.1.006

Zhang LB, Zhang GL, Tang ZH, Hong TY (2013) Relationships between ectoparasites and grooming behaviour of Tylonycteris pachypus and T. robustula. Zool Res 34:596-600. https://doi.org/10.11813/j.issn. 0254-5853.2013.6.0596

Publisher's Note Springer Nature remains neutral with regard to jurisdictional claims in published maps and institutional affiliations. 